\title{
O ENFRENTAMENTO DA PANDEMIA DA COVID-19 NA CENTRAL DE ABASTECIMENTO (CEASA) EM CURITIBA/PR
}

\section{COPING WITH THE COVID-19 PANDEMIC AT THE SUPPLY CENTER (CEASA) IN CURITIBA/PR}

\author{
Larissa Leonarda Pinto* \\ ORCID: https://orcid.org/0000-0001-5268-0640 \\ Pâmela Moreira Weinhardt** \\ ORCID: https://orcid.org/0000-0003-2234-1853 \\ Raphael Vieira Lopes*** \\ ORCID: https://orcid.org/0000-0002-6690-0445 \\ Erildo Vicente Müller**** \\ ORCID: https://orcid.org/0000-0003-4643-056X \\ Giovani Marino Favero***** \\ ORCID: https://orcid.org/0000-0002-1946-3262 \\ Rafael Gomes Ditterich****** \\ ORCID: https://orcid.org/0000-0001-8940-1836
}

\section{Resumo}

A pandemia da Covid-19 exigiu a adoção de medidas de prevenção, sendo o isolamento social a principal. Para evitar o desabastecimento, a atividade laboral de caminhoneiros foi considerada essencial e, por se manterem expostos, a categoria foi considerada grupo de risco. O objetivo deste estudo foi descrever as estratégias de ação de um projeto de extensão para o combate à pandemia, praticadas por uma equipe multiprofissional de saúde, na Central de Abastecimento em Curitiba. A metodologia foi constituída por cinco ações: reconhecimento territorial, formulação e distribuição de material educativo, verificação da temperatura corporal, orientações de higiene e uso de máscara. A equipe também se reuniu diariamente para partilhar e discutir experiências. Enfrentar uma pandemia é um grande desafio para profissionais de saúde, e atuar em projeto multiprofissional e intersetorial é uma experiência enriquecedora, ressaltando a importância da Promoção da Saúde no melhoramento das condições sanitárias do país.

Palavras-chave: Infecções por coronavírus; Saúde do trabalhador; Promoção da saúde.

\begin{abstract}
The Covid-19 pandemic required preventive measures and social isolation became the main one. To avoid shortages, the trucker drivers' activity was considered essential. Given the exposure of these workers, they were considered a risk group. Therefore, the aim of this study was to describe the strategies of preventive action, health care and combat to the Covid-19 pandemic, practiced by a multiprofessional health team, in the Supply Center unit in Curitiba. The methodological proposal was built strategically and included five actions: territorial recognition, formulation and distribution of educational material, verification of body temperature, hygiene instructions and the use of a mask. In addition, the group met to share experiences and progress. Coping with a pandemic is one of the biggest challenges for health professionals; working in a project with multiprofessional and intersectoral action is an enriching experience and clarifies the importance of Health Promotion in improving the country's health conditions.
\end{abstract}

Keywords: Coronavirus infections; Occupational health; Health promotion.

Data recebimento: $01 / 07 / 2020$

Data de aceite: $17 / 09 / 2020$
* Aluna de Mestrado da Universidade Federal do Paraná (UFPR), Curitiba - PR, Brasil. E-mail: plllarileonarda@gmail.com **Aluna de Mestrado da Universidade Federal do Paraná (UFPR), Curitiba - PR, Brasil. E-mail: pamelamw.ufpr@hotmail.com ***Aluno de Mestrado da Universidade Federal do Paraná (UFPR), Curitiba - PR, Brasil. E-mail: vieiralopesraphael@gmail.com **** Professor da Universidade Estadual de Ponta Grossa (UEPG), Ponta Grossa - PR, Brasil. E-mail: erildomuller@hotmail.com ***** Professor da Universidade Estadual de Ponta Grossa (UEPG), Ponta Grossa - PR, Brasil. E-mail: gmfavero@yahoo.com.br ****** Professor da Universidade Federal do Paraná (UFPR), Curitiba - PR, Brasil. E-mail: prof.rafaelgd@gmail.com 


\section{Introdução}

As Centrais de Abastecimento (CEASA) em todo o Brasil fazem parte do Programa Estratégico de Desenvolvimento e do Plano de Desenvolvimento do Governo Federal, estabelecidos na década de 70. No ano de 1990, o Governo do Estado assumiu as unidades do CEASA/PR. A unidade da capital, Curitiba, entrou em operação em 1976, no bairro Tatuquara, e é atualmente o maior centro de distribuição atacadista de alimentos da cidade e região metropolitana. A comercialização de produtos se dá por meio de permissionários (atacadistas) e produtores, totalizando a comercialização de 702.77 toneladas de alimentos por ano. Assim como em mais de $61 \%$ dos alimentos transportados no país, o abastecimento da CEASA/PR ocorre predominantemente via transporte rodoviário, por intermédio de caminhoneiros (SHITSUKA et al., 2019).

Em 11 de março de 2020, a Organização Mundial da Saúde (OMS) declarou estado de pandemia em relação à Covid-19, doença causada pelo vírus Sars-Cov-2, que pode se manifestar como uma síndrome gripal até infecção respiratória aguda, levando a óbito (OMS, 2020). Diante do exposto, foi necessário adotar medidas preventivas em todo o mundo. Para conter a propagação da doença, a medida mais eficaz identificada até o momento é o isolamento social, que consiste em restringir a circulação da população aos limites de suas moradias e fechamento do comércio e serviços considerados não essenciais (POSSÍDIO; MARTINEZ, 2020).

Além disso, foi necessária a obrigatoriedade do uso de máscara por toda a população, principal barreira física para reduzir o risco de contágio pelo novo coronavírus, já que um dos principais meios de transmissão do vírus são as gotículas de saliva que se espalham na fala, no espirro ou na tosse (OMS, 2020). Por fim, intensificou-se a orientação de cuidados básicos de higiene, como a lavagem adequada das mãos com água e sabão, e no caso desta impossibilidade, o uso do álcool em gel.

A greve de caminhoneiros ocorrida no Brasil em 2018 gerou rapidamente desabastecimento de uma variedade de itens por todo o país (LOPES et al., 2019). Diante dessa experiência, e agora, frente à de pandemia de Covid-19, a Associação Nacional do Transporte de Cargas e Logística declarou oficialmente apoio à continuidade das atividades da classe, para que a distribuição de suprimentos não fosse afetada (NTC\&LOGÍSTICA, 2020), evitando uma nova crise de abastecimento. Dessa forma, considera-se como serviço essencial a atividade exercida por caminhoneiros. A realidade desses profissionais, por sua vez, conta com longas jornadas de trabalho, ausência de pausas para descanso, má alimentação, risco de assaltos, acidentes de trabalho e outros fatores que podem prejudicar sua saúde e qualidade de vida, sendo que a hipertensão e a diabetes, consideradas fatores de risco para Covid-19, são doenças frequentemente relatadas pelos caminhoneiros (SILVA et al., 2016; CNT, 2020).

O contexto de pandemia trouxe a intensificação das atividades laborais para essa categoria; esses trabalhadores passaram a ser vistos como grupo vulnerável com maior risco de contaminação, bem como possíveis agentes de transmissão do vírus (por permanecerem 
em livre e ampla circulação). Nesse quesito, entende-se a relevância de ações voltadas para a Saúde do Trabalhador, visando conhecer a potencialidade da situação de trabalho (a atividade em si e as condições em que ocorre) como fontes de exposição à doença e estabelecer estratégias para enfrentar a pandemia (FIHO et al., 2020).

Frente a esse cenário, a Fundação Araucária, sensível ao enfrentamento da Covid-19, conjuntamente com a Superintendência Geral de Ciência, Tecnologia e Ensino Superior (SETI) e a Secretaria de Estado da Saúde (SESA) do Paraná, lança o Programa de Apoio Institucional para Ações Extensionistas de Prevenção, Cuidados e Combate à pandemia do Novo Coronavírus, para que as Instituições de Ensino Superior (IES) desenvolvam ações preventivas, de esclarecimento público, de levantamento de dados e de combate à pandemia da Covid-19 (FUNDAÇÃO ARAUCÁRIA, 2020).

Dentre as ações definidas, as equipes de atenção às divisas rodoviárias na $2^{\mathrm{a}}$ Regional de Saúde do Paraná foram então compostas por bolsistas de diferentes profissionais e estudantes de saúde para monitorar as condições de saúde de pessoas que estejam transitando pelas divisas rodoviárias do Estado do Paraná. Em especial atenção, um dos maiores locais de fluxo e trânsito de pessoas provenientes de diferentes localidades e estados encontram-se no CEASA/PR.

Dessa forma, o objetivo deste trabalho é descrever as etapas da ação de extensão desenvolvidas sobre prevenção, cuidados e combate à pandemia de Covid-19, praticadas por uma equipe multiprofissional, nas dependências da unidade Curitiba da CEASA/PR.

\section{Estratégias de ação de prevenção, cuidados e enfrentamento à pandemia da Covid-19}

A prática de orientação em saúde é uma medida pouco custosa se comparada a outras, como as que dependam do uso de tecnologias duras para serem executadas (FLORES et al., 2016), sendo uma das atribuições dadas aos profissionais da área pela Política Nacional de Promoção da Saúde (PNPS) (BRASIL, 2010). Os resultados positivos desse tipo de ação podem ser vistos nas diversas vertentes da saúde (FLORES et al., 2016; BOVO; WISNIEWSKI; MORSKEI, 2016; PASSOS; PINHO, 2016; BRIXNER et al., 2017; DE OLIVEIRA; BOTTA; RESELL, 2017; FERNANDES; VIEGAS; BRAZÃO, 2017).

Logo, a prática desenvolvida na CEASA/PR, unidade Curitiba, durante a pandemia da Covid-19, se amparou na premissa de "educar para prevenir". Para tanto, uma equipe multiprofissional de bolsistas (composta de duas enfermeiras, uma psicóloga, um farmacêutico, dois cirurgiões-dentistas e um fisioterapeuta, além de três acadêmicos de enfermagem e odontologia) trabalhou com ênfase na orientação educativa, ação que aconteceu sobre a coordenação da Universidade Estadual de Ponta Grossa (UEPG), em parceria com a Universidade Federal do Paraná (UFPR). 


\section{A proposta metodológica}

A proposta metodológica elaborada foi realizada de forma integrada e articulada com o território do CEASA/PR, contando com a participação de vários atores (bolsistas, coordenadores, gestor da CEASA/PR, representante da SESA, caminhoneiros, produtores, revendedores e pessoas que circulam nesse local). A proposta final, construída coletivamente, foi constituída estrategicamente por cinco ações a serem realizadas diariamente. Trata-se de cinco momentos que obedecem a um fluxo e que se retroalimentam, além de se intercomunicarem com as ações de enfrentamento da Covid-19, com ênfase nas ações de vigilância em saúde, tendo a pesquisa científica presente de modo transversal durante todo o processo, por meio do levantamento de dados empíricos destinados a um esforço investigativo posterior (Figura 1).

Figura 1 - Proposta metodológica com 5 ações integradas no enfrentamento da Covid-19 na CEASA/PR

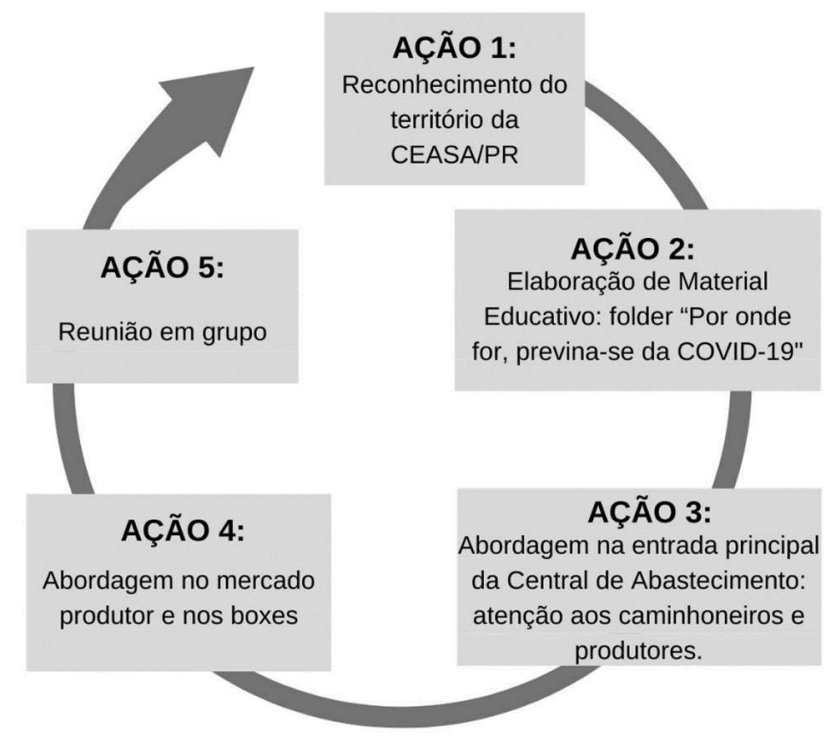

Fonte: Elaborada pelos autores

Anteriormente ao início do desenvolvimento das ações, os bolsistas foram capacitados pelos coordenadores do projeto, tendo recebido orientações quanto à forma e ao momento de abordagem, demonstração do uso correto do equipamento a ser utilizado e distribuição dos equipamentos de proteção individual (EPI's) a serem utilizados (máscara cirúrgica, viseira de proteção, coletes refletores e capas de chuva). Por fim, quanto à dinâmica de trabalho, ficou determinado que a equipe se dividiria em duplas, formadas por profissionais de áreas diferentes. 
As atividades executadas eram comuns a ambos, independentemente da formação. Os acadêmicos estariam sempre sob supervisão do profissional de sua área de formação.

\section{Ação 1: Reconhecimento do território do CEASA/PR}

Neste primeiro momento, a equipe de bolsistas realizou o reconhecimento e a forma de organização do espaço em que as ações seriam executadas, juntamente com os coordenadores do projeto e a direção da CEASA. Feito isso, ficou definido que a abordagem do grupo-alvo se daria primeiramente na entrada principal da CEASA, das 22 horas às 4 horas, sendo este 0 horário em que os caminhoneiros adentram no ambiente; esse momento seria dedicado à verificação de temperatura corpórea e orientações em saúde. Na sequência, das 5 horas às 8 horas, o desenvolvimento da atividade passaria a ocorrer nos boxes e pedras, assim denominado o local onde os produtores da região e intermediários, que recebem mercadoria, expõem os produtos para a venda, também com verificação de temperatura corporal e orientações.

Sabendo-se que há uma estimativa de fluxo de cerca de 2 mil pessoas circulando no local diariamente e dadas as condições de realização das atividades laborais que envolvem aglomerações de pessoas, esforço braçal e contato tanto físico como com diversas outras superfícies, o ambiente de trabalho da CEASA mostrou-se com grande potencial de propagação da Covid-19.

\section{Ação 2: Elaboração de Material Educativo: folder "Por onde for, previna-se da Covid-19"}

Especialmente para a realização desta ação, foi desenvolvido um folder educativo (Figura 2), em parceria com a UEPG, a Fundação Araucária e a Secretaria de Estado da Saúde (SESA), contando com o envolvimento de cinco bolsistas, três coordenadores do projeto e um enfermeiro da Secretaria Estadual de Saúde.

O conteúdo desse material foi composto por ilustrações de fácil compreensão sobre higienização pessoal básica e do caminhão, medidas de prevenção ao contágio da doença e, ainda, a descrição dos sinais e sintomas de alerta que indicariam a necessidade de atendimento ambulatorial. Além disso, divulgou e facilitou o acesso ao aplicativo de Telemedicina, modalidade de triagem e atendimento proposta pelo Governo do Estado (AEN/PR, 2020), especialmente para o cenário de pandemia da Covid-19. 
Figura 2 - Folder "Por onde for, previna-se da Covid-19!"
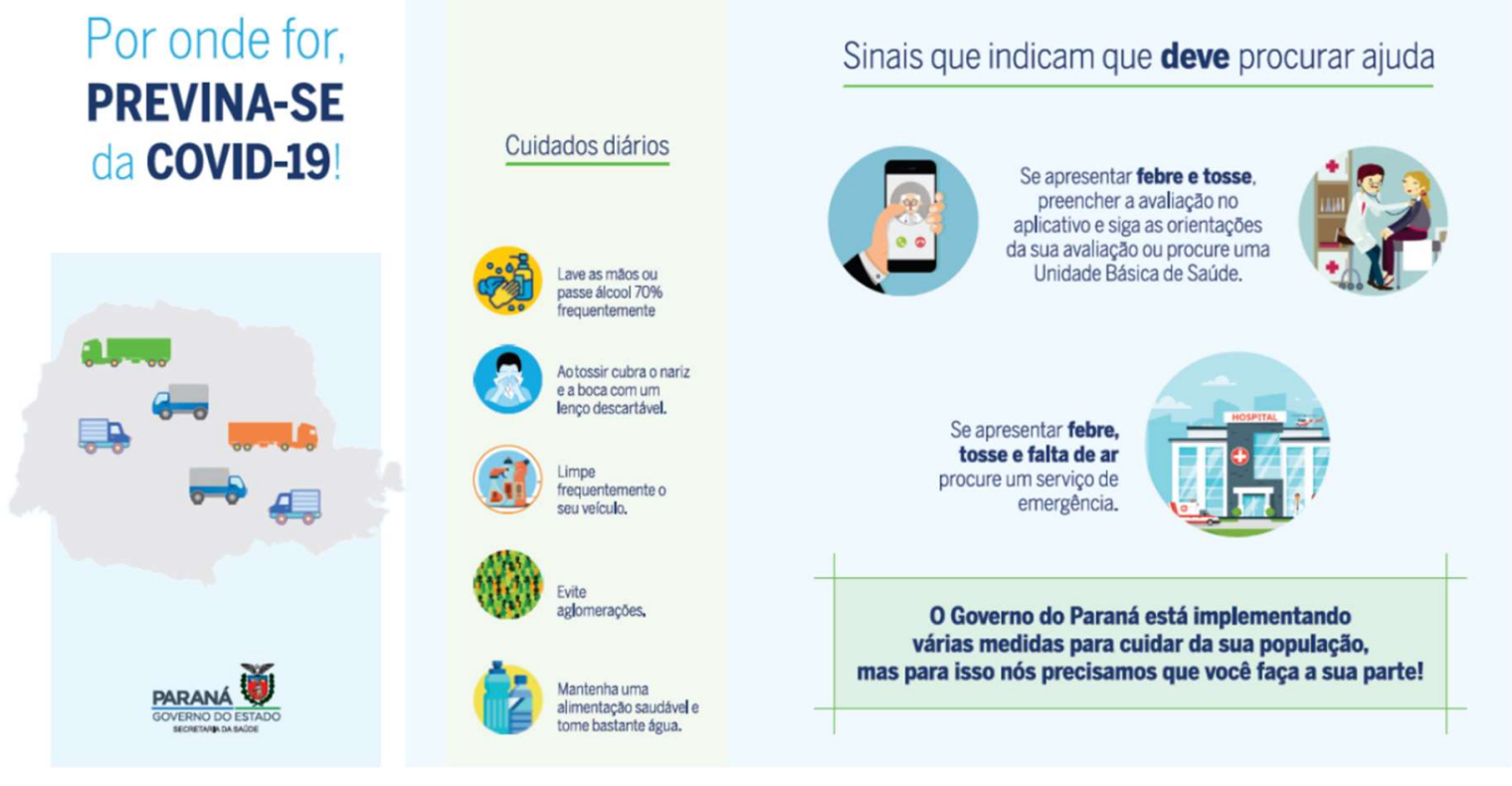

Fonte: Autores.

\section{Ação 3: Abordagem na Entrada Principal da Central de Abastecimento - Atenção aos caminhoneiros e produtores}

A primeira etapa desta ação ocorreu na entrada principal da CEASA/PR, no período noturno, onde todos os caminhoneiros realizam parada obrigatória para apresentar a Nota Fiscal de suas mercadorias e produtos aos funcionários da instituição. Nesse momento, os bolsistas abordavam os caminhoneiros e produtores, realizando busca ativa de sinais e sintomas da Covid-19 (questionando sobre a presença de tosse, febre, falta de ar, entre outros) e verificando suas temperaturas corporais por meio de um termômetro do tipo infravermelho.

Além disso, a prática conta com a distribuição de material educativo, o qual reforça as orientações de higiene, atenção aos sinais e sintomas e sobre o direcionamento aos serviços de saúde no caso de indivíduos suspeitos. Essa prática foi realizada por meio de conversa, em tom informal, de modo que os indivíduos abordados se sentissem acolhidos, evitando-se gerar a sensação de coação, pois os profissionais poderiam ser vistos como fiscais e não agentes promotores de saúde. Os dados eram registrados em formulário (Figura 3). 
Figura 3 - Formulário para registro de sintomas relatados pelos indivíduos abordados na CEASA/PR.

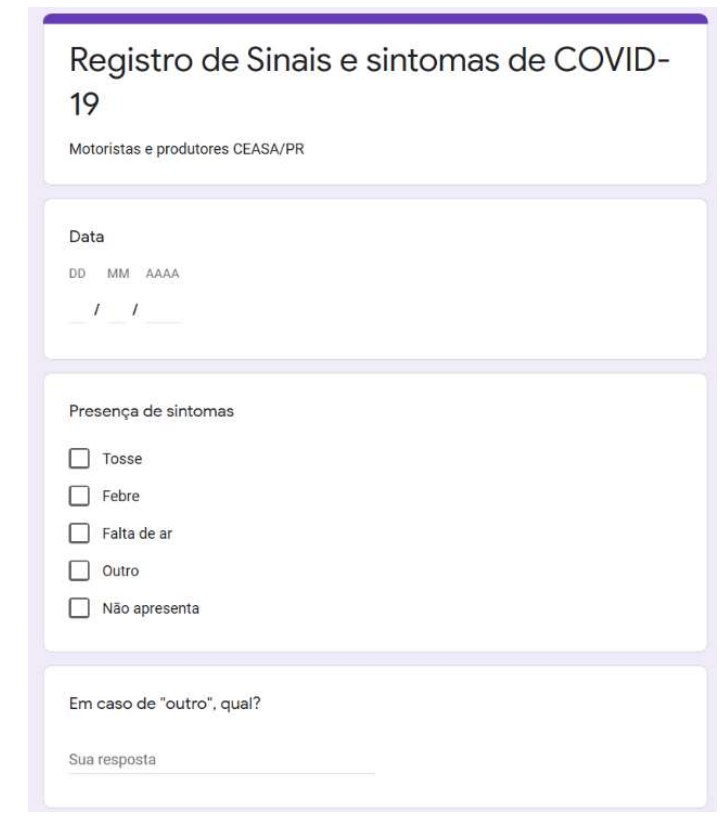

Fonte: Autores.

A partir do Decreto Municipal de Curitiba n ${ }^{\circ}$ 470/2020 e da Lei Estadual 20.189/2020, publicados em março e abril de 2020, respectivamente, que tornaram obrigatório o uso de máscara em ambientes coletivos, a equipe passou a vigiar e orientar o cumprimento das normativas, observando se aqueles que adentravam no ambiente estavam vestindo-a e, em caso de negativa, questionando quanto à posse do item. Para os indivíduos que não possuíam o EPI, seja caminhoneiros, acompanhantes, compradores ou "chapas" (trabalhadores avulsos que prestam serviços a várias empresas, sem vínculo empregatício, e que na CEASA carregam e descarregam caminhões de hortifrutigranjeiros e outros), eram oferecidas máscaras de tecido, cedidas pela CEASA/PR (CURITIBA, 2020; PARANÁ, 2020), e também eram prestados esclarecimentos quanto à forma correta de utilização, bem como sua importância na prevenção de transmissão e contaminação da Covid-19.

As atividades ocorreram sempre no período das 22 horas às 4 horas, que corresponde ao limite de entrada dos produtores e caminhoneiros representantes dos varejistas. De maneira geral, os caminhoneiros e outros frequentadores da CEASA/PR reagiram com receptividade à abordagem feita na entrada principal, muitos traziam suas dúvidas quanto ao panorama da pandemia e faziam questão de mostrar seus itens de higiene e proteção individual, como máscaras e álcool em gel. 
Observou-se que, de forma unânime, os indivíduos abordados relataram não apresentar nenhum sintoma quando questionados e apenas duas vezes verificou-se temperatura corporal acima de $37,5^{\circ} \mathrm{C}$. A partir do início da vigilância quanto ao uso de máscara de proteção, notou-se maior resistência do público, que passou relatar sentimento de coação pela compulsoriedade de utilização do EPI.

\section{Ação 4: Abordagem no mercado produtor e nos boxes}

A unidade Curitiba da CEASA/PR conta com 644 boxes (local onde os varejistas comercializam) e 86 pedras (local onde os produtores locais comercializam). Possui 4.534 produtores cadastrados, além de 84 lojas, 13 lanchonetes e 50 flores (local onde são comercializadas flores), cujas atividades se iniciam às 4 h30min.

Nesta fase das ações, ocorreram rondas em equipe, verificando-se novamente as temperaturas corporais, reforçando-se as orientações de higiene e esclarecendo-se dúvidas. A partir da publicação da Lei Estadual (20.189/2020), que torna obrigatório o uso de máscara, iniciou-se também a observação do seu cumprimento, gerando um relatório diário dos locais (Figura 4) onde não ocorria o uso do EPI, para entrega aos responsáveis pela fiscalização no interior da CEASA.

Dada a composição abrangente e diversa do público-alvo, o início dessa última ação foi pouco aceita. Com o desenvolvimento das atividades, percebeu-se maior adesão das orientações passadas, contudo, a alimentação do relatório diário sobre o cumprimento do uso obrigatório de máscara evidenciou a resistência de parte dos indivíduos, que insistiam em não usar o EPI ou utilizá-lo de forma inadequada (como máscara apoiada no pescoço) mesmo após recebidas as orientações. Além disso, a dinâmica de trabalho que ocorre na CEASA não proporciona o distanciamento entre os trabalhadores, gerando diariamente aglomerações.

Figura 4 - Modelo do relatório diário a respeito do cumprimento do uso obrigatório de máscara

Relatório diário sobre o cumprimento da Lei Estadual 20.189/2020 CEASA/PR

\begin{tabular}{|c|c|c|c|}
\hline Data & $\begin{array}{c}\text { Tipo de } \\
\text { estabelecimento } \\
\text { (pedra ou boxe) }\end{array}$ & $\begin{array}{c}\text { Identificação do } \\
\text { estabelecimento } \\
\left(\mathbf{n}^{\circ} \text { ) }\right.\end{array}$ & $\begin{array}{c}\text { Presença de indivíduos } \\
\text { descumprindo a ordem de uso } \\
\text { obrigatório de máscara? (sim/não) }\end{array}$ \\
\hline & & & \\
\hline & & & \\
\hline & & & \\
\hline
\end{tabular}

2. Resumo das atividades executadas

3. Considerações

Fonte: Autores 


\section{Ação 5: Reunião em grupo}

Ao fim das rondas, a equipe se reunia no Espaço Saúde, no interior da unidade da CEASA/PR, para debater o processo de trabalho do dia, expondo suas críticas, experiências, expectativas e formas de melhorar as ações propostas, sempre buscando avançar enquanto grupo e atingir o objetivo maior do projeto, que é a prevenção, cuidado e enfrentamento à pandemia da Covid-19. As pautas debatidas nas reuniões eram registradas em documentos de processamento de texto e, ao final de cada mês, enviadas aos coordenadores do projeto, a fim de que estivessem cientes das impressões da equipe.

\section{Discussão}

No Brasil, mais de $60 \%$ das cargas são deslocadas via transporte rodoviário, sendo o modal mais utilizado no país. Responsável por conectar todos os setores econômicos, essa modalidade é a única que permite que os produtos cheguem ao consumidor final sem terem que passar por outra forma de condução; essa facilidade tem papel direto na cadeia de produção (ao reduzir custo para as empresas produtoras) e no consumo (a sua eficiência pode influenciar no preço final dos itens) e, portanto, torna o país dependente de sua atividade.

Com relação ao setor hortifrutigranjeiro, a experiência recente da greve dos caminhoneiros, em maio de 2018, deixou evidente que, sem o transporte rodoviário de alimentos, o desabastecimento dessa qualidade de carga se dá muito rapidamente, o que foi sentido em algumas cidades do país já no terceiro dia de paralisação da categoria de trabalhadores. Além disso, a realidade da unidade Curitiba da CEASA/PR é predominantemente de agricultura familiar, que, assim como em outros locais do Brasil (REIS; MOREIRA; CUNHA, 2017), representa a principal forma de obtenção de proventos das famílias de agricultores locais, sendo muitas vezes a única. Esse cenário foi determinante para manter pleno o desenvolvimento das atividades de trabalho dessa população, mesmo durante a pandemia.

A declaração de pandemia da Covid-19 gerou pânico e uma corrida desenfreada aos supermercados pôde ser vista ao redor do mundo, trazendo consigo carência de insumos, especialmente dos mais básicos (MELLO et al., 2020). Tal cenário possibilita a visualização da importância da manutenção da atividade dos caminhoneiros, que atuam como personagens essenciais de prestação de serviços, para que a população brasileira mantenha o acesso aos alimentos mesmo em tempos de crise de saúde pública.

Nesse sentido, o funcionamento da CEASA/PR, como maior centro de distribuição atacadista da Grande Curitiba, é de extrema importância para que todos os 29 municípios estejam providos da qualidade de itens de hortifruti; para que a Central de Abastecimento continue funcionando, por sua vez, é imprescindível que também o façam os caminhoneiros 
que a tenham como destino de suas cargas. Contudo, o momento de incerteza gerou nesses trabalhadores, assim como em toda a sociedade, o sentimento de medo (AGUIAR et al., 2020) e levou, em um primeiro momento, a adoção de criteriosos meios de proteção individual, como o uso de máscara de proteção, conforme as recomendações do Ministério da Saúde (GARCIA, 2020). Nesse momento, foi possível observar a adesão dos caminhoneiros ao projeto, que viam na equipe o cuidado necessário para aquele momento.

Em contrapartida à essencialidade da função dos caminhoneiros, o cenário que se estabeleceu demonstrou a extrema necessidade de suas atividades laborais, o que acabou por aumentar a demanda de trabalho. A ampla circulação dessa categoria e, muitas vezes, as condições que encontram para desenvolver suas atividades atuam como fatores de exposição e de transmissão do vírus, como é o caso na CEASA/PR, onde é possível observar, além de aglomeração de pessoas, o contato compartilhado por várias superfícies. Nessas condições, ser caminhoneiro em meio a uma pandemia viral torna essa população vulnerável e com maior risco de contaminação, exigindo atenção especial das autoridades e gestores de saúde pública, com foco na Saúde do Trabalhador, para traçar estratégias que minimizem as mazelas advindas dessa realidade, além das demais mazelas que a categoria já enfrenta: privação de sono, extensa e extenuante carga horária, falta de oferta para manutenção de uma dieta saudável, entre diversas outras.

A pouca assistência em saúde e as más condições de trabalho dos caminhoneiros, embora bastante conhecidas (SILVA et al., 2016), não foram relatadas pelo público atendido durante o projeto. Também não houve registro de indivíduos que apresentassem sinais e sintomas da doença causada pelo novo coronavírus. Atribui-se tal achado a um possível receio de que, ao relatar sua condição clínica, haja o impedimento de trabalhar nas dependências da CEASA, comprometendo gravemente a renda da família, fato que pode, portanto, estar associado ao medo do desemprego que tem se mostrado corriqueiro (SOUZA SEDANO et al., 2010; AFONSO, 2020).

O conflito político que se instalou acerca das medidas necessárias para frear a epidemia, associado à rede de desinformação instaurada pelas fake news sobre esse momento de instabilidade, e a ineficiência e demora do Estado em garantir renda mínima à população trouxeram um cenário de caos (SOUSA JÚNIOR et al., 2020; BRANDÃO, 2020). Essa realidade pode ser observada entre os caminhoneiros da CEASA através do discurso e resistência em aderir às recomendações de proteção individual após alguns meses, fato que não foi notado em um primeiro momento, onde o medo era maior que o ceticismo.

Por se tratar de uma classe de trabalhadores pouco assistida, projetos extensionistas como o que gerou este estudo, que levem à reflexão de seus hábitos e auxiliem na busca e estabelecimento de saúde, são necessários e devem ser articulados com entidades que garantam sua continuidade (FRANCO et al., 2019). A utilização de material didático, como o folder "Por onde for, previna-se da Covid-9!", com ilustrações e instruções simples 
apresentam grande capacidade de auxiliar a tomada de decisão do público, o que também é relatado em outros estudos (SOBRINHO-SANTOS et al., 2015).

Em tempos de crise de saúde pública e a necessidade de contingência de danos, na qual o setor de abastecimento tem papel essencial, o trabalho multidisciplinar e intersetorial se faz fundamental. Enquanto a provisão de alimentos e demais itens de primeira necessidade não pode ser interrompida, os trabalhadores acabam se expondo aos riscos de contaminação e transmissão da doença, e, por isso, devem receber amparo do setor de Saúde, para que, além da prevenção haja garantia de que essa engrenagem permanecerá a pleno funcionamento.

Para tanto, no desenvolvimento de toda atividade, todos os atores devem ser preparados para se protegerem, mas também para compreenderem que suas atividades têm papel fundamental no combate à pandemia (FIHO et al., 2020). Torna-se, então, um desafio trabalhar com a educação em saúde com a classe de caminhoneiros (SOUZA SEDANO et al., 2010), especialmente com as individualidades e a onda de desinformação do momento. Por fim, fica evidente a importância da educação em saúde, contudo, também a dificuldade de atingir os seus objetivos rapidamente, o que leva à clara necessidade de que esta prática seja adotada como estratégia transversal nos cuidados de saúde (PALÁCIO; TAKENAMI, 2020).

\section{Considerações Finais}

A declaração de pandemia e o enfrentamento de uma doença pouco conhecida são os maiores desafios profissionais daqueles que escolheram atuar na área da saúde. O comprometimento, a objetividade e a união de forças para sua superação são necessárias para a minimização dos efeitos da transmissão da doença. As ações multiprofissionais elucidam de forma prática a importância da Promoção da Saúde no melhoramento das situações e condições sanitárias do país.

Atuar no enfrentamento da pandemia da Covid-19 exige construção coletiva, responsabilidade e planejamento efetivo e contínuo de ações, como as descritas neste artigo, por meio das atividades propostas na ação de extensão com os caminhoneiros e pessoas que circulam no CEASA/PR. A participação em um projeto como este proporciona aliar conhecimentos e experiências das diversas áreas da saúde, tornando-se uma oportunidade profissional enriquecedora, individualmente ou como grupo. Fica evidente a importância de que a diretriz da atenção multiprofissional seja cada vez mais fortalecida, para que os saberes e experiências se somem e agreguem valor às Ciências da Saúde, sempre em prol da saúde pública. 


\section{Referências}

AGÊNCIA ESTADUAL DE NOTÍCIAS DO ESTADO DO PARANÁ - AEN/PR. Governo do Paraná implanta telemedicina para atendimentos da Covid-19 [internet]. 2020. Agência de Notícias do Estado. Disponível em: $<$ http://www.aen.pr.gov.br/ $>$. Acesso em: 30 abr. de 2020.

AGUIAR, V. G.; RAMOS JÚNIOR, D. V.; COSTA, K. G.; DIAS, R. S. D. L. S. Notificando o medo: cartografia e percepção da COVID-19 na malha rodoviária na porção norte dos vales dos Rios Araguaia e Tocantins. Hygeia-Revista Brasileira de Geografia Médica e da Saúde, v. 16, n. Edição Especial: COVID-19, p. 153-163, 2020.

AFONSO, P. The Impact of the COVID-19 Pandemic on Mental Health. Acta Médica Portuguesa, 33, n. 13, 2020.

FRANCO, S. E. J.; HORA, D. J.; ARAUJO, G. G.; LEMES, A. G.; ROCHA, E. M. Benefícios do projeto de extensão Viva Bem Caminhoneiro para motoristas. Revista Panorâmica, v. 2, p.69-82, 2019.

BRANDÃO, V. O papel do Estado como garantidor de emprego e renda durante a pandemia do novo Coronavírus [internet]. 2020. (Boletim Finde 01-maio/2020 - Covid 19 e os desafios do desenvolvimento). Niterói: FINDE, UFF, 2020. Disponível em: $<$ http://financeirizacaoedesenvolvimento.uff.br/wp-content/uploads/sites/43/2020/05/\%C3\%B3rioFinde-01-maio-2020.pdf> Acesso em: 03 ago 2020.

BRASIL. Ministério da Saúde. Política Nacional de Promoção da Saúde. Brasília: Ministério da Saúde; 2010.

BOVO, F.; WISNIEWSKI, P.; MORSKEI, M. L. M. Atenção Farmacêutica: papel do farmacêutico na promoção da saúde. Bio saúde, v. 11, n. 1, p. 43-56, 2016. ISSN 2525-555X.

BRIXNER, B. et al. Ações de promoção de saúde nas estratégias saúde da família. Cinergis, v. 18, p. 386-390, 2017.

CONFEDERAÇÃO NACIONAL DO TRANSPORTE - CNT. Perfil dos Caminhoneiros 2019 [internet]. 2020. Confederação Nacional do Transporte. Disponível em: $<$ https://cnt.org.br/>. Acesso em: 28 abr. de 2020. 
CURITIBA. Decreto n. ${ }^{\circ}$ 470, de 26 de março de 2020. Estabelece medidas complementares para o enfrentamento da Emergência em Saúde Pública, decorrente do novo Coronavírus (Covid-19) e define os serviços públicos e as atividades essenciais que devem ser resguardados pelo Poder Público e pela iniciativa privada. Diário Oficial do Município, 26 de março de 2020.

FERNANDES, P.; VIEGAS, S.; BRAZÃO, R. Educar para prevenir: materiais sobre higiene e segurança dos alimentos baseado em evidência científica. Boletim Epidemiológico Observações, v. 6, n. 20, p. 29-31, 2017.

FIHO, J. M. J.; ASSUNÇÃO, A. Á.; ALGRANTI, E., GARCIA E. G., SAITO, C. A., MAENO, M. A saúde do trabalhador e o enfrentamento da COVID-19. Revista Brasileira de Saúde Ocupacional, v. 45, p. e142, 2020. Disponível em: <

https://www.scielo.br/pdf/rbso/v45/2317-6369-rbso-45-e14.pdf> Acesso em: 06 ago 2020.

FLORES, T. R.; NUNES, B. P.; ASSUNÇÃO, M. C. F.; BERDOLDI, A. D. Hábitos saudáveis: que tipo de orientação a população idosa está recebendo dos profissionais de saúde? Revista Brasileira de Epidemiologia, v. 19, p. 167-180, 2016.

FUNDAÇÃO ARAUCÁRIA. Chamada Pública no 09/2020. Ação de Extensão contra o Novo Coronavírus. 2020. Disponível em: <http://www.fappr.pr.gov.br/>. Acesso em: 30 abr. de 2020.

GARCIA, L. P. Uso de máscara facial para limitar a transmissão da COVID-19. Epidemiologia e Serviços de Saúde, 29, p. e2020023, 2020.

LOPES, A. S.; CORREA, J. D. S.; SILVA, T. C.; RODRIGUES, Y. S. Os impactos gerados pela greve dos caminhoneiros no Brasil e a resiliência nos equipamentos e serviços turísticos. Cenário, v. 7, n.12, p. 59-72, 2019.

MELLO, G.; OLIVEIRA, A. L.; GUIDOLIN, A. P.; CASO, C.; DAVID, G.; NASCIMENTO, J. C.; GONÇALVES, R.; SEIXAS, T. A Coronacrise: natureza, impactos e medidas de enfrentamento no Brasil e no mundo. Centro de Estudos de Conjuntura e Política Econômica - IE/UNICAMP. Nota do Cecon, n.9, março de 2020. Disponível em: < http://www3.eco.unicamp.br/images/arquivos/nota_cecon_coronacrise_natureza_impactos_ e_medidas_de_enfrentamento.pdf $>$ Acesso em: 06 ago $20 \overline{2} 0$.

NTC\&LOGÍSTICA. Nota Oficial - Coronavírus (COVID-19) [internet]. 2020. Associação Nacional do Transporte de Cargas e Logística (NTC\&Logística). Disponível em: <https://www.portalntc.org.br/>. Acesso em: 28 abr. de 2020. 
OLIVEIRA, A. L. B. M.; BOTTA, A. C.; RESELL, F. L. Promoção de saúde bucal em bebês. Revista de odontologia da universidade Cidade de São Paulo, v. 22, n. 3, p. 247 253, 2017.

PALÁCIO, M. A. V.; TAKENAMI, I. Em tempos de pandemia pela COVID-19: o desafio para a educação em saúde. Vigilância Sanitária em Debate: Sociedade, Ciência \& Tecnologia, v. 8, n. 2, p. 10-15. 2020.

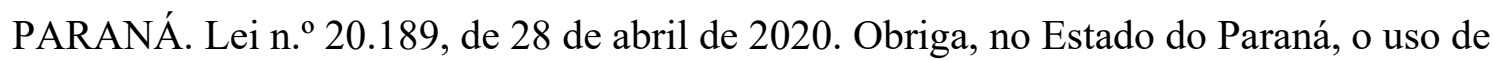
máscaras enquanto perdurar o estado de calamidade pública em decorrência da pandemia do coronavírus SARS-CoV-2, e adota outras providências. Diário Oficial do Estado n ${ }^{\circ} 10675$ de 28 de Abril de 2020.

PASSOS L. P.; PINHO L. Profissionais de saúde na promoção ao aleitamento materno: revisão integrativa. Revista de Enfermagem UFPE on line, v. 10, n. 3, p. 1507-1516, 2016. ISSN 1981-8963.

POSSÍDIO, C.; MARTINEZ, L. O trabalho nos tempos do Coronavírus. Saraiva Educação AS, 2020. ISBN 6555591269.

REIS, C. V. S.; MOREIRA, T. B. S.; CUNHA, G. O efeito marginal do capital humano na agricultura familiar. Revista Espacios, 38, n. 23, p. 8, 2017.

SHITSUKA, D. M.; TORRES, D. B. G. R.; SILVA, P. C. D.; SHITSUKA, R. Caminhoneiros e o senso comum na sociedade brasileira. Research, Society and Development, v.8, n.2, p. e1082568, 2019.

SILVA, L. G. D.; LUZ, A. A.; VASCONCELOS, S. P.; MARQUEZE, E. C.; MORENO, C. R. C. Vínculos empregatícios, condições de trabalho e saúde entre motoristas de caminhão. Revista Psicologia Organizações e Trabalho, v. 16, n. 2, p. 153-165, 2016.

SOBRINHO-SANTOS, C. K.; SILVA, A. V. D.; MALHEIROS, A. F.; TRINDADE, R. A. D. et al. Relatos de caminhoneiros sobre a prevenção do HIV e o material educacional impresso: reflexões para educação em saúde. Ciência \& Educação (Bauru), 21, n. 4, p. 1011-1030, 2015.

SOUSA JÚNIOR, J. H.; RAASCH, M.; SOARES, J. C.; RIBEIRO, L. V. H. A. S. Da Desinformação ao Caos: uma análise das Fake News frente à pandemia do Coronavírus (COVID-19) no Brasil. Cadernos de Prospecção, v. 13, n. 2, Edição Especial, p. 331-346, 2020. 
SOUZA SEDANO, G.; FERREIRA, S. C. M.; VALENTE, G. S. C.; CHRISOSTIMO, M. M. Educação em saúde: um desafio do enfermeiro do trabalho na atenção à saúde dos caminhoneiros. Revista de Pesquisa Cuidado é Fundamental Online, 2, n. 2, p. 760-769, 2010.

WORLD HEALTH ORGANIZATION. WHO Director-General's remarks at the media briefing on 2019-nCoV on 11 March 2020. Genebra: OMS, 2020. 